\title{
Research on National Image Construction and Cross-Cultural Communication in International Video Course Based on New Media Technology
}

\author{
Ke Wang ${ }^{1, a}$
}

\author{
${ }^{1}$ Beijing International Studies University, Beijing, China \\ awangke7808@126.com
}

\begin{abstract}
The construction and communication of national image is not only an important part of the national development strategy, but also an important aspect of Chinese culture "going out". With the development of the Internet and new media technology, it provides more convenient tools and means for the publicity of national image. This paper attempts to explore how to use new media technology to consciously shape and publicize national image in the international video course.
\end{abstract}

Keywords: new media technology, national image construction, cross-cultural communication studies

\section{INTRODUCTION}

The construction and communication of national image is an important part of the national development strategy. Not only is it a significant factor for a country to attract the attention and investment of the world, but also it is a very important publicity work in the process of the rise and development of a country. A good national image is the core component of a country's soft power and an important driving force to enhance the country's international competitiveness. A good national image means higher credibility, greater acceptance and wider space for international cooperation and development. In the era of globalization, with more and more countries realizing the importance of national image construction and communication, they work hard to improve their international images[1]. The construction of national image and cross-cultural communication are becoming the most important game strategies between countries in the international political and economic competition. How to establish the national image of contemporary China and how to carry out a continuous and effective communication of national image in order to show China's image to the world and make them get familiar with and accept China, are important topics for the construction of national soft power and the expansion of national influence.Nowadays, the network new media technology is able to transcend tangible national boundaries and barriers, break through the time-space constraints of real communication and provide a convenient platform for communication of national image, which extends the breadth and depth of communication between people at home and abroad. The reason that the communication of national image relies more and more on the network new media and social media is due to its open and inclusive technical traits, which effectively break through and remove the restriction and hindrance of different cultural identities, enhance the communicative atmosphere, and achieve the interactive effects. Therefore, the cross-cultural construction and communication of national image requires us to recognize the current international and domestic situations in the first place[2]. We should strengthen our work from the aspects of overall strategic construction, cross-cultural differences research, cross-cultural multiple communication, characteristic discourse, comprehensive publicity brand and so on. We should use new media technologies to better promote the cross-cultural construction and publicity of China's national image.

\section{PROBLEMS IN CROSS-CULTURAL CONSTRUCTION AND COMMUNICATION OF NATIONAL IMAGE}

By using the international video conference system, Beijing International Studies University has carried out cross-cultural international courses with several universities in the United States, Mexico, Thailand, Vietnam, Taiwan, etc. During the classes, we found that students from these counties and areas are more interested in traditional Chinese culture.

\subsection{Existing Problems}

2.1.1. Due to historical or realistic reasons, the communication of China's image in other countries or regions remains undistinguished. The news reports about China are often negative and deviated from the actual situation, especially in the countries which have historical disputes on major issues or potential conflicts in strategic development with China[3]. It is very obvious in the exchanges with universities in Taiwan. Our students generally have a natural affinity for Taiwanese students, but Taiwan students tend to show indifference and resistance. Thus, students from both sides are lack of deep communication and common cultural identity.

2.1.2. Different situations and development paths of different countries might lead to the misunderstanding of each others. Meanwhile, countries and regions in the world differ greatly in their development models and paths. Their national strengths and conditions vary from country to country. In another word, countries in the world still have a long way to 
go towards a better life[4]. It is not likely to expect that each country can have a positive image in another country, which is evident in exchanges with universities in the United States and Vietnam.

2.1.3. Because of the differences of language and culture, it is difficult to guarantee the proper understanding of national image. Although the world has already entered the era of globalization, and the world is increasingly becoming a global village, the language and culture, religious beliefs, customs and habits of various countries are quite different, which is obvious in the process of communication with Mexican and Thai college students. Therefore, the publicity of national image must be considered from many aspects, instead of being simply carried out. Only when we attach importance to cross-cultural communication can we effectively guarantee the communication of national image, and ensure that the national image is recognized and positively evaluated.

2.2. At present, in the process of cross-cultural construction and communication of China's national image, the cross-cultural awareness of Chinese citizens is found to be relatively weak. Although China is a multi-ethnic country, it does not have much experiences in cross-cultural communication. On one hand, the gaps among subcultures in China are relatively small, because the culture of all ethnic groups in China has always been infiltrated and nurtured by the same Chinese civilization for a long time. Therefore, the problems faced by cross-cultural communication in domestic subculture are significantly less than those in foreign cultures. On the other hand, most western countries have the history of foreign cultural immigration, especially the United States, which gained rich cross-cultural experience. However, fewer immigrants are received in China while most of Chinese emigrated to foreign countries. For most Chinese people, cross-cultural awareness and cross-cultural ability tend to be weak or superficial. The difficulties and potential problems in the development of our country might still become inevitable problems in the construction and publicity of our national image. This may include environmental issues, food safety issues, intellectual property protection issues, corruption issues, polarization between the rich and the poor, and so on. In the course of constructing and publicizing the new national image, these problems may accompany us for a period of time, and foreign students are very likely to focus on these problems as well.

This paper attempts to use the methods of discourse analysis and case studies in the international video course to explore how to shape and spread the national image in cross-cultural communication with the aid of new media technology.

\section{DISCOURSE ANALYSIS AND CASE STUDY}

3.1. First, we should study the cultural differences between China and foreign countries, and vigorously promote the study of foreign culture, especially the study of different countries, regions and national cultures. The cultures of various countries in the world are diverse, and the national culture is even more colorful. If we deal with the world only in English and look at the complex and diverse world through the lens of the British and American culture, it is obviously difficult to grasp the real sides of other cultures.
The diversity of languages and cultures around the world requires us to cultivate more talents who are familiar with foreign languages, especially those who are fluent in minority language. Besides, more experts and professionals who master minority cultures should be highly valued[5]. 3.2. Second, we should expand multiple ways in cross-cultural communication. Not only should we attach importance to the purposeful image construction and communication of the state and the government, but also we should value the chips that non-governmental organizations and citizens can add to the national image in cross-cultural communication activities. The images of overseas companies, overseas tourism and overseas work of various personnel are often amplified into the national image of the country. To construct and communicate the national image, we can not only pay attention to the role of traditional media, especially newspapers, television and films, but also pay attention to the new challenges brought by new media.

3.3. In addition, it is necessary to establish a characteristic discourse system. To do a good job in cross-cultural communication of China's national image, an important aspect is to put forward a discourse system with Chinese characteristics. National image is not only an abstract issue, but also something that can be implemented into concrete objects. According to the Chinese characteristics, it is necessary to set an agenda that both Chinese and foreign parties can participate in. To construct and spread China's image, we can use stories that attract people from all over the world, apply acceptable narrative modes and topics that the world cares about, and use discourse styles that the world can understand[6]. We should set up specific communication content, discursive framework and expression according to the features of different cultures and languages. We should also strengthen the research on the promotion mode and core words of the world's important media. What's more, it should be pointed out that there are obvious differences in thinking modes, cultures and discourse expressions between China and the West. These differences, after long-term accumulation, will be concentrated in people's cognition of many things. Also, the concerns of the two sides may not be completely consistent, and people might not fully understand or even misunderstand each other. Therefore, what kind of words, what content, when and where to communicate are worth studying and exploring.

3.4. It is necessary to be aware of the new situation of cross-cultural construction and communication of China's national image. In the practice of cross-cultural construction and communication, we should do well in the top-level design and locate the image of our country in a practical position. We should vigorously promote the study of regional culture and characteristic culture, strengthen the construction of multiple cross-cultural communication media, create a national image discourse system with Chinese characteristics, improve the overall quality of the citizens, and strive to build a brand of cultural communication. We should get rid of the illusory positioning and avoid emphasizing only the form rather than the construction of content and substance. We should not take the simple traditional image as the direction of communication, not pursue the output of ideology, not use the words of others to build ourselves, and avoid the impetuous and impatient mentality.

3.5. We should be prepared to use the power of new media 
[5] Liu Dan, The building and communication of national image in cross-cultural context, Zhejiang University, master's thesis.

[6] Wu Lili, Brief analysis on how to effectively play the role of network media in national image communication, Reform \& Openning, in December 2010.

[7] Liu Yang, On cultural communication and national image building in the context of globalization, Journal of Yangtze Normal University, April 2014, Vol. 30, No. 2.

\section{CONCLUSION}

As the crystallization of human wisdom, the Internet new media technology has become a global public platform for the collision and integration of contemporary cultural exchanges, and a new channel for communication between different national cultures. We need to follow the trend of human development and bridge differences and gaps through the Internet new media communication context. We should promote the integration of Chinese and western ideas, expand the scope and level of communication, and innovate effective forms and methods of communication. We should improve the communication ability in a targeted way through the use the Internet tools, the application of new media technology and the construction of the common emotional dimension for Chinese and foreign students. Hopefully, in this way, foreign students can recognize and accept our national image.

\section{REFERENCES}

[1] Liang Xiaobo, Cross cultural construction and communication of China's national image, Journal of Wuhan University (Philosophy and Social Sciences), Vol. 67, No. 1.

[2] Fan Hong, The Strategy for National Image Building and Communication, Journal of Tsinghua University(Philosophy and Social Sciences), 2013, issue 2 (Volume 28).

[3] He Ping, National image building and cultural soft power construction, Cultural Soft Power, 2016, issue 1.

[4] Huang Lin, New dimensions of image communication between China and India in the context of the Internet, Forum on Chinese Culture, October 2016. 